\title{
Relationship between systolic blood pressure and decision-making during emotional processing
}

Sophie Betka, MSc, ${ }^{1,2,4}{ }^{*}$, David Watson, $\mathrm{PhD},^{1}$, Sarah Garfinkel, PhD, ${ }^{1,3}$, Gaby Pfeifer, PhD, ${ }^{1}$, Henrique Sequeira, PhD, Dr ès Sci., ${ }^{4}$, Theodora Duka, MD, ${ }^{2,5}$, and Hugo Critchley, DPhil, FRCPsych, ${ }^{1,3}$

${ }^{1}$ Brighton and Sussex Medical School, Clinical Imaging Science Centre, Brighton, BN1 9RY, UK

${ }^{2}$ University of Sussex, Behavioural and Clinical Neuroscience, School of Psychology, Brighton, BN1 9QH, UK

${ }^{3}$ Sackler Centre for Consciousness Science, University of Sussex, UK

${ }^{4}$ University of Lille, SCALab, CNRS UMR 9193, Lille, 59045, France

${ }^{5}$ Sussex Addiction Research and Intervention Centre (SARIC), University of Sussex, UK

*corresponding author: sophie.betka@epfl.ch

Address: Trafford Centre, Brighton and Sussex Medical School, Clinical Imaging Science Centre, Brighton, BN1 9RY, UK

Tel: 0044 (0) 1273873132 Fax: 0044 (0) 1273876721

Word count $=5262(<6500)$

Running head: Body-Brain interaction in alexithymia

Conflicts of Interest and Source of Funding. Authors have no conflicts or other disclosures beyond funding information provided. The present study was supported in part by Rotary Foundation, the Society for the Study of Addiction and the European Research Council (Advanced Grant CCFIB AG 234150 awarded to HDC). Sophie Betka is grateful to the Society for the Study of Addiction (SSA) for funding support under their PhD Studentship scheme, and states that the opinions expressed are those of the author(s) and do not necessarily reflect the views of the SSA itself. 


\begin{abstract}
Objective: Emotional states are expressed in body and mind through subjective experience of physiological changes. In previous work, subliminal priming of anger prior to lexical decisions increased systolic blood pressure (SBP). This increase predicted the slowing of response times (RT), suggesting that baroreflex-related autonomic changes and their interoceptive (feedback) representations, influence cognition. Alexithymia is a subclinical affective dysfunction characterized by difficulty in identifying emotions. Atypical autonomic and interoceptive profiles are observed in alexithymia. Therefore, we sought to identify mechanisms through which SBP fluctuations during emotional processing might influence decision-making, including whether alexithymia contributes to this relationship.
\end{abstract}

Methods Thirty-two male participants performed an affect priming paradigm and completed the Toronto Alexithymia Scale. Emotional faces were briefly presented $(20 \mathrm{~ms})$ prior a short-term memory task. RT, accuracy and SBP were recorded on a trial-by-trial basis. Generalized mixed-effects linear models were used to evaluate the impact of emotion, physiological changes, alexithymia score, and their interactions, on performances.

Results A main effect of emotion was observed on accuracy. Participants were more accurate on trials with anger primes, compared to neutral priming. Greater accuracy was related to increased SBP. An interaction between SBP and emotion was observed on RT: Increased SBP was associated with RT prolongation in the anger priming condition, yet this relationship was absent under the sadness priming. Alexithymia did not significantly moderate the above relationships.

Conclusions Our data suggest that peripheral autonomic responses during affective challenges guide cognitive processes. We discuss our findings in the theoretical framework proposed by Lacey and Lacey (1970).

Keywords (up to 6): Systolic blood pressure (SBP), Baroreflex, Alexithymia, Affective priming, Emotion, EFE 
bioRxiv preprint doi: https://doi.org/10.1101/2021.10.22.465429; this version posted October 27, 2021. The copyright holder for this preprint (which was not certified by peer review) is the author/funder, who has granted bioRxiv a license to display the preprint in perpetuity. It is made available under aCC-BY-NC 4.0 International license.

Abbreviations: $\mathrm{AIC}=$ Akaike Information Criterion; $\mathrm{AUQ}=$ Alcohol Use Questionnaire; $\mathrm{EFE}=$

Emotional Facial Expression; IAPE = Implicit Affect Primes Effort (IAPE); PMM =Predictive Mean

Matching; SBP = Systolic Blood Pressure; TAS-20 = Toronto Alexithymia Scale-20 items. 


\section{Introduction $(\sim<\mathbf{1 5 0 0})$}

Emotional feeling states originate in part through subjective experience and cerebral representation of peripheral physiological reactions to affective stimuli (James, 1884; Lange, 1912). Bodily changes also inform and influence perceptual experience, allocation of attentional resources, emotional processing and decision-making (Bechara, Tranel, Damasio, \& Damasio, 1996; Garfinkel et al., 2016; Gray, Minati, Paoletti, \& Critchley, 2010; Makovac et al., 2017; Makovac et al., 2015; H. D. Park, Correia, Ducorps, \& Tallon-Baudry, 2014; Łukowska, Sznajder, \& Wierzchoń, 2018). One experimental means of testing how autonomic changes influence cognition is the use of an affective priming paradigm. Here, the emotional valence of a briefly presented stimulus (i.e. the prime) affects the processing of subsequent stimuli. Typically, if the prime and the target are of the same valence, a facilitatory effect (e.g. reduced reaction times) is observed. If the valence is different, an inhibitory effect is observed (e.g. increased reaction times) relative to a non-valenced control condition. In some forms of this paradigm, the prime is followed by a stimulus that prompts performance of a task, e.g. making a lexical decision (Hull, Slone, Meteyer, \& Matthews, 2002). For example, the subliminal presentation of the word "ANGER" (vs "RELAX") as a prime, just prior to rapid judgments of letter-strings, increases systolic blood pressure in healthy individuals. Here, the magnitude of this increase predicts RT prolongation on the task (Garfinkel et al., 2016). Increased systolic blood pressure is also observed in priming studies using emotional faces (Gendolla \& Silvestrini, 2011; Lasauskaite, Gendolla, \& Silvestrini, 2013; Silvestrini \& Gendolla, 2011b, 2011c) (for review see van der Ploeg, Brosschot, Versluis, \& Verkuil, 2017). Affect primes are proposed to activate affective mental representations influencing physiological reactivity (Gendolla, 2012), informing behavioral responses via afferent (interoceptive) feedback. However, in some forms of emotional dysfunction including alexithymia, the representation, and integration of interoceptive bodily responses appears to be impaired.

Alexithymia is a personality construct classically defined by difficulties in describing and identifying ones’ own emotional feelings (Apfel \& Sifneos, 1979; Taylor, Ryan, \& Bagby, 1985). Alexithymic 
subjects show abnormal affective regulation characterized by reduced emotional faces recognition, delayed automatic rapid facial reactions, reduced empathy, reduced emotional awareness, abnormal emotional remapping and higher body representation malleability (Georgiou, Mai, \& Pollatos, 2016; Grynberg et al., 2012; Grynberg \& Pollatos, 2015; Lane, Hsu, Locke, Ritenbaugh, \& Stonnington, 2015; Moriguchi et al., 2007; Scarpazza, Ladavas, \& Cattaneo, 2017; Scarpazza, Ladavas, \& di Pellegrino, 2015).

Recent work suggests that interoceptive failure (e.g. reduced sensitivity to bodily sensations) is core to emotional impairments observed in alexithymia (Betka et al., 2017; Bird et al., 2010; Brewer, Cook, \& Bird, 2016; Hogeveen, Bird, Chau, Krueger, \& Grafman, 2016; J. Murphy, Catmur, \& Bird, 2017; Shah, Hall, Catmur, \& Bird, 2016). Indeed, visceral arousal informs the complex experience of subjective feelings (Critchley \& Harrison, 2013; Shah, Catmur, \& Bird, 2017; Tsakiris \& Critchley, 2016). For example, one channel communicating cardiovascular arousal originates in afferent signals from arterial baroreceptors localized in the aorta and carotids. The arterial baroreflex is a homeostatic mechanism that minimizes fluctuation in blood pressure through coupling afferent baroreceptor signals to efferent control of heart rate, cardiac output and peripheral resistance (Brading, 1999; Eckberg \& Sleight, 1992). Observations in hypertensive patients can inform our understanding of how interoceptive abnormalities may underlie the expression of alexithymia. In hypertension, abnormalities of the baroreflex mechanism are observed, including reduced baroreflex sensitivity (Mussalo et al., 2002). Hypertensive patients are also reported to show impaired interoceptive abilities during a heartbeat detection task (Yoris et al., 2017).This deficit is observed independently of heart rate or heart rate variability (HRV; an index of parasympathetic cardiac control) and exteroceptive abilities remain preserved (Yoris et al., 2017).This disruption of interoceptive processing in hypertensive patients is likely to contribute to the association between raised resting systolic blood pressure and impaired emotional processing (McCubbin et al., 2011; Pury, McCubbin, Helfer, Galloway, \& McMullen, 2004). These findings suggest important significance of blood pressure on aspects of interoception. 
Conversely, peripheral autonomic abnormalities are documented in alexithymic subjects who are at increased risk of premature death and cardiovascular disease (Helmers \& Mente, 1999; Kauhanen, Kaplan, Cohen, Julkunen, \& Salonen, 1996; Kauhanen, Kaplan, Cohen, Salonen, \& Salonen, 1994; Tolmunen, Lehto, Heliste, Kurl, \& Kauhanen, 2010). Dampened autonomic reactivity to emotional challenges or stress supports a hypoarousal model of alexithymia (Cecchetto, Korb, Rumiati, \& Aiello, 2018; Constantinou, Panayiotou, \& Theodorou, 2014; Neumann, Sollers, Thayer, \& Waldstein, 2004; Peasley-Miklus, Panayiotou, \& Vrana, 2016; Pollatos et al., 2011). However, there is yet no conclusive evidence for an association between alexithymia and abnormal baroreflex sensitivity (Virtanen et al., 2003). Alexithymic individuals report higher self-reported anxiety and show greater systolic blood pressure reactivity during the stress of blood donation (Byrne \& Ditto, 2005). During anger recall, alexithymic individuals have attenuated cardiac responses (Neumann et al., 2004) but then show hampered recovery (of diastolic blood pressure recovery and cardiac preejection period), compared to non-alexithymic individuals (Neumann et al., 2004). Nevertheless, alexithymia is more prevalent among hypertensive patients than in the general population (Gage \& Egan, 1984; Jula, Salminen, \& Saarijarvi, 1999; Todarello, Taylor, Parker, \& Fanelli, 1995).

A few studies have tested affective priming effects in alexithymia, but with variable methodologies. Priming by verbal stimuli is reportedly enhanced in alexithymia (Suslow, 1998), and greatest for negative primes when emotionally congruent with targets (Suslow, Junghanns, Donges, \& Arolt, 2001). In a third study using different types of prime/target associations (e.g. verbal-verbal; facial-verbal; verbal facial etc.), alexithymia also reportedly moderates the impact of angry face primes on the evaluative judgment of an affective target, the effect apparent across verbal, visual and cross-modal trials (Vermeulen, Luminet, \& Corneille, 2006). When primes and targets are specifically related to illness (e.g. verbal prime: “dizziness"), alexithymia was associated with faster reaction times for negative and positive verbal primes to illness-related targets (Brandt, Pintzinger, \& Tran, 2015). These studies do not report implicit physiological responses. 


\subsection{Aims and hypotheses}

Therefore, we sought to identify the relationship between physiological changes evoked by emotional primes (indexed by systolic blood pressure) and cognition (indexed by accuracy and speed of decisionmaking). A second aim was to explore whether alexithymia contributed to this relationship.

We expected that greater accuracy and shorter reaction times on a short-term / working memory task will be predicted by increased systolic blood pressure in the emotional priming conditions (anger and sadness) compared to the neutral priming condition.

Also, we hypothesized that alexithymia may partly mediate the relationship between physiological changes and decision-making through its association with increased systolic blood pressure at rest.

Given the well documented co-occurrence of depression, anxiety and alcohol use disorders in alexithymia (Finn, Martin, \& Pihl, 1987; Hendryx, Haviland, \& Shaw, 1991), we additionally assessed these variables in order to control for potential cofounding effects. 


\section{Methods}

\subsection{Participants}

Thirty-two male volunteers (mean age 25.1 yrs; range 18-36yrs) took part in the experiment, based on a sample size calculation using statistical information from a similar study (Garfinkel et al., 2016). The present study contributed to the baseline session of a larger project looking at the impact of intranasal oxytocin on emotional regulation processes. For this reason, only male participants were recruited, via poster advertisements placed around the University of Sussex and Brighton and Sussex Medical School. All participants were healthy, with no history of psychiatric or neurological diseases. The average number of years of education was $\mathrm{M}=16.9(\mathrm{SD}=2.6)$. All participants gave their written informed consent and were compensated $£ 7$ per hour for their time. The study was reviewed and approved by the BSMS Research Governance and Ethics committee.

\subsection{Material}

\subsection{Stimuli}

A modified version of a Sternberg Task (e.g. item-recognition paradigm involving short-term / working memory) was designed(Sternberg, 1966). Ninety-six strings of seven letters were selected (e.g. KOPLTFV, IZTNLDS). Each presentation of a letter-string was followed by visual mask then the presentation of a target letter. The target letter was present in half of the letter-string trials. During the experiment, the letter-string was preceded by a visual prime: a very short presentation of an image displaying an emotional facial expression (EFE) of sadness, anger or neutrality. For each of these affective conditions, there were 32 trials (32 letter-strings preceded by an EFE of sadness, 32 letter-strings preceded by an EFE of anger, 32 letter-strings preceded by an EFE of neutrality). The EFE, coloured and from front perspective, were chosen from the Karolinska Directed Emotional Faces battery (Goeleven, De Raedt, Leyman, \& Verschuere, 2008, for list of stimuli codes see the supplementary section). Trials were 
presented in blocks of four consecutive trials of the same EFE, balanced and randomised for male/female gender. This cognitive task was run using Matlab.

\subsection{Physiological recording}

Blood pressure was recorded using non-invasive, beat-to-beat monitoring via photoplethysmographic technology (Finometer PRO, Finapres medical systems, Amsterdam, The Netherlands). An inflatable finger cuff and infrared plethysmograph were fitted to the middle finger of the participant's left hand, allowing measurements of beat-to-beat systolic blood pressure. The heart level electrode was attached to participant's clothing in the mid-clavicular line at the level of the heart. Physiological data was recorded using Spike software 26.08 .

\subsection{Questionnaires}

\subsubsection{Toronto Alexithymia Scale-20 items (TAS-20)}

The TAS-20 (Bagby, Parker, \& Taylor, 1994) consists of 20 items rated on a five-point Likert scale (from 1 "strongly disagree" to 5 "strongly agree"). Exploratory factor analysis and confirmatory factor analyses demonstrated that TAS-20 had a good internal consistency (Cronbach's $\alpha=0.81$ ), a good test-retest reliability $(0.77, \mathrm{p}<0.01)$ and a three-factor structure, in both clinical and non-clinical populations (Haviland, Shaw, MacMurray, \& Cummings, 1988; Taylor et al., 1988). The TAS-20 is composed of three factors. The first factor measures difficulties in identifying feelings (DIF), the second factor measures difficulties in describing feelings (DDF) and the third factor measures the way the participant uses externally oriented thoughts (EOT). The total alexithymia score is the sum of responses across all 20 items. We only considered the total score in our analyses. High alexithymic are characterised by a score > or $=61$; non alexithymic are characterised by a score $<$ or $=51$; between 50 and 60 , subjects are characterised as intermediate.

\subsubsection{Trait Anxiety (STAI)}


Trait anxiety was assessed using the Trait version of the Spielberger State/Trait Anxiety Inventory (STAI; Spielberger et al., 1983). This questionnaire is composed of 20 questions, assessing trait anxiety with questions such as "I lack self-confidence" and "I have disturbing thoughts". Participants were asked to answer each statement using a response scale which runs from $1=$ "Almost never" to $4=$ "Almost always" in order to capture a stable dispositional tendency (trait) for anxiety.

\subsubsection{Beck Depression Index II (BDI)}

Symptoms and severity of depression were evaluated using the BDI (Beck, Steer, Ball, \& Ranieri, 1996). Participants responded to 21 questions designed to assess the individual's level of depression (e.g. Sadness, pessimism, past failure etc.). The BDI items are scored on a scale from 0-3. All items were then summed for a BDI total score.

\subsubsection{Alcohol Use Questionnaire (AUQ)}

The AUQ (Mehrabian \& Russell, 1978) is a 15-item scale measuring in a detailed way the quantity of alcohol consumption (alcohol units of $8 \mathrm{~g}$ drunk per week). For the past six months, participants were asked to estimate the number of drinking days, the usual quantity consumed and drinking pattern. For the purpose of our study, we used only the drinking quantity (i.e. alcohol units per week).

\subsection{Procedure}

The study was conducted at the Clinical Imaging Science Centre in Brighton, United Kingdom. Participants were asked to abstain drinking $24 \mathrm{~h}$ before the experiment and gave fully informed consent. Demographic data (e.g. age, education level) were recorded and psychometric questionnaires were administered. Participants were breathalyzed and a urinary sample was collected to test for drug use. Task instructions were explained again and an inflatable Finometer finger cuff was then fitted to participants' middle finger. After a 5 min recording calibration period, the participant was invited to start the Sternberg Task (Gendolla \& Silvestrini, 2011). Each trial began with a 1000 ms fixation cross, followed by the EFE (20 ms) and a backward Mondrian mask (125 ms). This rapid series of events was immediately followed 
by a string of seven letters that remained on screen for $750 \mathrm{~ms}$, followed by a backward mask of seven "X" letters $(750 \mathrm{~ms})$. Then a target letter appeared at the centre of the screen until participants made a decision (max 2000ms), denoting whether or not the target letter was present in the earlier letter-string by pressing the right or the left arrow key, respectively. Next, a visual analogue scale allowed participants to rate their confidences for each trial, from "zero" to "extreme" (3000ms). In case of non-response, the message "Please answer more quickly" was presented during 3000ms. Finally, an inter stimuli interval of randomised duration (between 100 to $300 \mathrm{~ms}$ ) was added before the beginning of the next trial. The maximum duration of a trial was $7 \mathrm{~s} 645 \mathrm{~ms}$. Participants were encouraged to answer as quickly and accurately as possible. Reaction times (RT) and accuracy were recorded. The order in which these blocks were presented was randomized. Pilot study data showed participants would be unaware of the emotional nature of the prime stimulus (Gendolla \& Silvestrini, 2011). However this was not formally confirmed for each individual trial in the main study.

\subsection{Data analyses}

\subsubsection{Behavioural data processing}

One participant was excluded due to a depression score above three standard deviations of the mean. Reaction time on the Sternberg task and accuracy of response were recorded for each trial. Very fast reaction times $(<$ or $=100 \mathrm{~ms}$ ) were deleted (Whelan, 2008). Missing data were quantified. Seventy-six reaction times data points were missing on a total of 1240 observations. Rather than deleting these cases, we performed multiple imputation using predictive mean matching. Predictive mean matching (PMM) is a semi-parametric imputation approach which imputes missing values by means of the nearest-neighbour donor with a distance based on the expected values of the missing variables conditional on the observed covariates (Little, 1988) We calculated these using the Multiple Imputation by Chained Equations (MICE) package in R, with PMM as method of imputation and the number of imputations set at 5 (Van Buuren \& Groothuis-Oudshoorn, 2011). Imputed data were checked and included in the dataset. 


\subsubsection{Physiological data processing}

Inter-beat-Interval (IBI, ms), beat-to-beat values of systolic blood pressure (mmHg; from Finapres) and event-related information were extracted from recordings in Spike. Physiological data were smoothed using a Gaussian function (set to 1 ) to create a constant signal over systolic peaks and average across potential spike artefacts. Events data were aligned and binned at $100 \square \mathrm{Hz}$. All data were exported to Matlab (MATLAB and Statistics Toolbox Release 2016a, The MathWorks, Inc., Natick, Massachusetts, United States). Trial-by-trial systolic blood pressure levels values were derived from the averaged height of systolic peaks between the EFE presentation and the end of the VAS presentation over each trial.

\subsection{Statistical Analyses}

\subsubsection{Correlations}

Mean and standards deviations were computed for reaction time, accuracy and systolic blood pressure. Physiological and behavioral measures were correlated to psychometric data, using 2-tailed nonparametric correlations.

\subsubsection{Mixed effects linear models}

We used mixed-effects modeling to test effects of the variables (accuracy, reaction times (RT) and systolic blood pressure (SBP)), measured on trial by trial basis, (Barr, Levy, Scheepers, \& Tily, 2013).

Accuracy was analyzed using a generalized linear mixed model as the outcome was binary (binomial family; Inaccurate =0; Accurate $=1$ ). To satisfy normality assumption, reaction times were also analyzed using a generalized linear mixed-effects model (Lo \& Andrews, 2015). After fitting different density to the observed reaction times distribution, the relative quality of the models was estimated using Akaike information criterion (AIC). The lower AIC (e.g. best fit) was observed when a Gamma distribution was fitted to the observed reaction time distribution. 
The same basic model was tested for each of the two outcomes (i.e. accuracy and reaction time). The basic model included systolic blood pressure, emotion (3 levels: Neutrality=0; Sadness=1; Anger=2), TAS score and the interactions terms as predictors. Therefore, intercept reflects the outcome value in the neutral condition. Given the established influence of age on blood pressure reactivity, age was included in the basic model as a control variable. Finally, participants were specified as a random (subject) factor, allowing for random intercepts.

The basic model was then compared to a similar model that also included anxiety, depression and alcohol intake to test confounding effects of these variables, contrasting the goodness of fit of the models using likelihood ratio tests.

All continuous predictors were mean-centered prior being entered in models. Analyses were undertaken using the lme4 package (Bates, Maechler, Bolker, \& Walker, 2015). For models including a random term, the default lme4 optimizer was used. Finally, $p$ values were computed using lmerTest package (Kuznetsova, Brockhoff, \& Christensen, 2014). All analyses were run in the R environment (version 3.4.2; RCoreTeam, 2013).

\subsubsection{Post-hoc analyses: Heart rate variability}

In order to explore if accuracy, reaction times and systolic blood pressure were related to a deceleration at the heart rate level, we analysed the heart rate variability in the frequency domain. To do so, we used the software HRVAS (Ramshur, , http://sourceforge.net/projects/hrvas/?source=navbar). The Lomb-Scargle method was preferred as this method provides power spectral density estimates of unevenly sampled data (Laguna, Moody, \& Mark, 1998). For each participant, we computed mean interbeat interval, low cardiac frequencies percentage $(0.04 \mathrm{~Hz}$ to $0.15 \mathrm{~Hz})$, high cardiac frequencies percentage $(0.15 \mathrm{~Hz}$ to $0.4 \mathrm{~Hz})$ and the ratio low-to-high cardiac frequencies. Finally, mean and standards deviations were computed for each variable. Physiological measures were correlated to behavioural data, using 2-tailed nonparametric correlations. 


\section{Results}

\subsection{Mean, standard deviations, correlation and sample characterisation}

Means, standard deviations, ranges, and correlation coefficients between psychometric, physiological and behavioral measures, are presented in Error! Reference source not found.. We did not observe suprathreshold correlations across psychometric data, behavioral and physiological measures. Moreover, in this sample, we found also no positive correlation between alexithymia and resting systolic blood pressure. Concerning alexithymia scores, 10 participants were characterized as non alexithymic (32.26\%), 10 participants were classified as intermediate (32.26\%), 11 participants were classified as alexithymic $(35.48 \%)$.

\subsection{Accuracy}

Accuracy was analyzed with emotion (3 levels: Neutrality=0; Sadness=1; Anger=2), systolic blood pressure, TAS and their interactions as fixed factors. The participant (subject) variable was defined as a random factor (see methods section). The model controlled for age. The distribution was set as binomial (see Error! Reference source not found.).

There was a main effect of emotion; anger primes elicited increased accuracy compared to sadness and neutrality conditions $(\beta=-0.50, \mathrm{SE}=0.13, p<.001$; see Figure 1$)$. A main effect of systolic blood pressure was also observed: increased systolic blood pressure was further also related to increased accuracy $(\beta=1.56, \mathrm{SE}=0.6, p<.050)$. Interaction between systolic blood pressure and emotion (anger vs neutrality) was observed as a trend: Here, low systolic blood pressure was associated with better accuracy in the anger condition compared to the neutral condition. However, increased blood pressure led to similar accuracy in both conditions $(\beta=-1.14, \mathrm{SE}=0.64, p=.070$; see Figure 2$)$. Interaction between TAS-20 and systolic blood pressure was also observed as a trend: While in non-alexithymic individuals, performance accuracy correlated positively with systolic blood pressure, alexithymic individuals showed increased accuracy at lower systolic blood pressures and their gain in accuracy with increasing systolic 
blood pressure was reduced compared to non-alexithymic individuals $(\beta=-0.1, \mathrm{SE}=0.05, p=.058$; see

Figure 3). There was furthermore a main effect of age $(\beta=-0.06, \mathrm{SE}=0.03, p<.050)$. Addition of control variables (anxiety, depression, alcohol intake) to the model did not significantly improve the goodness of fit (Basic model: AIC $=2586.9$; Model with covariates: $\mathrm{AIC}=2590.4$; comparison: $\chi^{2}(3)=$ $2.53 ; p=.470)$.

\subsection{Reaction Time}

Reaction times were analyzed with emotion (3 levels: Neutrality=0; Sadness=1; Anger=2), systolic blood pressure, TAS and their interactions as fixed factors. The participant variable was defined as a random factor (see methods section above). The model controlled for age. The distribution was set as gamma. (see Error! Reference source not found.).

There was an interaction between systolic blood pressure and emotion (sadness vs. neutrality conditions): For neutral (and anger) primes, increases in systolic blood pressure was associated with prolongation of reaction times. However, increases in blood pressure during the sadness prime condition were associated with faster reaction times $(\beta=-0.20, \mathrm{SE}=0.06, p<.001$; see Figure 4$)$. A main effect of systolic blood pressure on reaction time was observed as a trend $(\beta=-0.14, \mathrm{SE}=0.08, p=.090)$. Addition of control variables (anxiety, depression, alcohol intake) to the model did not significantly improve the goodness of fit (Basic model: AIC $=736.17$; Model with covariates: AIC $=741.50$; comparison: $\chi^{2}(3)=0.67 ; p=$ $.880)$. 


\subsection{Post-hoc analyses}

Means, standard deviations, and ranges, as well as uncorrected correlation coefficients between physiological and behavioral measures, are presented in Table 4. We observed a negative correlation between mean interbeat interval and correct responses percentage: greater accuracy was associated with increased heart rate $(\tau=-.323, p=.012)$. Reaction times were negatively correlated with low frequencies percentage suggesting an association between shorter reaction times and increased sympathetic (or mixed) activity $(\tau=-.254 ; p=.045)$. We did not observe suprathreshold correlations across HRV-related measures and systolic blood pressure. 


\section{Discussion $(\sim<1500)$}

In this present study, we tested how systolic blood pressure changes influence cognition during the processing of emotional primes, and explored how alexithymia might contribute to this relationship. We found an effect of emotional arousal on the accuracy of letter-string judgments: individuals were more accurate in their judgments when primed by angry faces compared to neutral faces. Moreover, better accuracy was associated with increased systolic blood pressure, regardless of the emotion. However, systolic blood pressure interacted also with the emotion quality of the prime on reaction time responses, where increasing blood pressure slowed reaction times following anger and neutrality primes but did not impact responses following sadness primes. We saw no direct moderating effect of alexithymia on accuracy or reaction times in our participants. Alexithymia did not correlate with blood pressure level. Nevertheless, a trend of interaction between systolic blood pressure and alexithymia on performance accuracy was still observed. Non-alexithymic individuals were more accurate in conditions associated with increased systolic blood pressure. In fact, alexithymic individuals were more accurate under low blood pressure compared to non-alexithymic individuals, whereas the inverse was observed under high blood pressure. Overall, alexithymic participants did not seem to benefit cognitively from blood pressure increases as much as non-alexithymic participants.

Our first main finding was an effect of arousal of the affective primes on decision-making accuracy. Here, participants were more accurate on the Sternberg task after being primed by angry faces compared to neutral faces. These results are coherent with existing literature: briefly flashed visual anger stimuli influence behavior, even without stimulating explicit affective responses (Gendolla, 2012; S. T. Murphy \& Zajonc, 1993; Winkielman, Berridge, \& Wilbarger, 2005). Anger is a negative-valenced and particularly salient emotion, which preferentially captures attentional resources (Burra, Barras, Coll, \& Kerzel, 2016; Burra, Coll, Barras, \& Kerzel, 2017; Feldmann-Wustefeld, Schmidt-Daffy, \& Schubo, 2011; Hodsoll, Viding, \& Lavie, 2011; Pinkham, Griffin, Baron, Sasson, \& Gur, 2010; Shasteen, Sasson, \& Pinkham, 2014). Presentation of angry face stimuli can increase visual short-term memory and working 
memory via modulation of basal ganglia activation (Jackson, Wolf, Johnston, Raymond, \& Linden, 2008; Jackson, Wu, Linden, \& Raymond, 2009). One potential explanation for increased accuracy after anger priming is the triggering of a hypervigilant state by the emotional anger prime, enhancing attentional deployment, which improves task performance. Alternatively, when primed by anger, the participants experienced a subjective reduction in task demand and a consequent increased ease in performance, when compared to the neutral and sadness priming conditions (Chatelain, Silvestrini, \& Gendolla, 2016; Gendolla \& Silvestrini, 2011). The latter is consistent with the coupling of anger to appetitive and approach motivational systems (Carver \& Harmon-Jones, 2009; Russell, 2003). Angry facial expressions facilitate the generation of approach rather than avoidance motor responses (Wilkowski \& Meier, 2010) and dynamic angry faces increase motor corticospinal excitability, mediating implicit and automatic responses to threat (Hortensius, de Gelder, \& Schutter, 2016).However, here we did not find a main effect of emotion on reaction times.

Our second main finding, nevertheless, was a significant interaction between priming condition and systolic blood pressure. In both anger and neutral priming conditions increases in systolic blood pressure evoked increased reaction times. However, this linear relationship was absent in the sadness priming condition: reaction times did not seem to be modulated by systolic blood pressure changes. Moreover, in the sadness condition, lower systolic pressure was associated with longer reaction times. Blood pressure increases following verbal anger primes have been previously observed to predict a prolongation of reaction time on a lexical task (Garfinkel et al., 2016). The difference between these effects of anger and sadness primes parallels earlier findings: Sadness primes during an easy task can increase cardiovascular responses compared to anger primes, yet in a difficult task, the inverse pattern is found (Freydefont, Gendolla, \& Silvestrini, 2012). Moreover, even masked sadness stimuli are associated with greater perceived difficulty and less ease when performing tasks (increased reactions times) and, therefore, increase the likelihood of disengagement when task demand becomes excessive (Silvestrini \& Gendolla, 2011a, 2011c). However, our data did not show any reaction time prolongation during the sadness 
condition, as might be predicted by the implicit affect primes effort (IAPE) model of Gendolla as a sign of disengagement.

Our third main finding was that, on a trial-by-trial basis, task performance accuracy was related to increased systolic blood pressure. These data extend the existent literature. As shown by intra-arterial recordings, a sympathetic mechanism is implicated in engendering the blood pressure increases that accompany simple reaction-time tasks, (Obrist et al., 1974; Paller \& Shapiro, 1983). Lower blood pressure correlates with poorer performance on a visuospatial attentional task in young hypotensive women (Cellini, Covassin, de Zambotti, Sarlo, \& Stegagno, 2013; Wharton et al., 2006). Moreover, pharmacological elevation of blood pressure improves cognitive performance in hypotensive patients (Duschek, Hadjamu, \& Schandry, 2007). Typically a rise in blood pressure activates arterial baroreceptors, which ultimately inhibit both cardiac and cortical activity, impacting cognitive processes (Kimmerly, 2017; Rau, Pauli, Brody, Elbert, \& Birbaumer, 1993). Natural or artificial baroreceptor stimulation can inhibit somatosensory afferent information flow (including pain) (Angrilli, Mini, Mucha, \& Rau, 1997; Gray et al., 2010). This cardiac afferent mechanism is postulated to reduce input from the external environment and, thereby reduce inattention and distractibility. Correspondingly, our data (i.e. higher systolic blood pressure, higher accuracy), accompanied possibly by heartrate deceleration (reducing afferent cardiac feedback to the brain and thereby limiting interference with cognitive processes) might have been broadly in line with the notion of an increase in attentive observation of the environment (Lacey \& Lacey, 1970). Speculatively, our observed increased blood pressure could have regulated cardiac output - via vagal influences. This control might have thus facilitated sensorimotor performance (Cellini et al., 2013; G. Park \& Thayer, 2014; G. Park, Vasey, Van Bavel, \& Thayer, 2013). Indeed, cardiac deceleration is itself modulated by arousal (e.g. threat) supporting the hypothesis of an evolutionary survival strategy (Hare, Wood, Britain, \& Shadman, 1970; Libby, Lacey, \& Lacey, 1973). However, we are cautious as we only observed a statistical trend in the interaction between blood pressure and emotion on performance accuracy. For the neutral condition, increased systolic blood pressure was 
associated with greater accuracy. First, we recognised the relevance of this observation to Lacey and Lacey's (1970) hypothesis. This model describes an association between cardiac deceleration and attention (or 'intake') directed to stimulations from the external environment; congruent with the lowerlevel inhibitory influence on sensory processing and cortical excitability induced by baroreceptor activation. To test the Lacey and Lacey's hypothesis, we conducted post-hoc analyses. These showed that greater accuracy and shorter reaction times were associated with faster heart rate and an increase in power of low frequency heart rate variability, respectively. Given the absence of an association between heartbeat deceleration or increased parasympathetic activity index (e.g. high cardiac frequencies) and accuracy, our data do not seem to support Lacey and Lacey's hypothesis. Instead, the rise in systolic blood pressure and the greater accuracy seem to be both driven by increased arousal induced by affective priming. This interpretation is congruent with the observed increased accuracy, in the absence of a modulation bodily state, under anger priming condition. Moreover, this discrepancy between different emotional conditions suggests the involvement of emotion-specific pathways (Brooks et al., 2012; Lacey \& Lacey, 1970). Also, it is important to specify that regression analyses do not allow determining whether the association between performance and physiological reactivity reflects a causal influence of the later to the former. For example, task performance and physiological activity might be both independent but parallel consequences of effortful cognitive processes, as proposed by the IAPE model (Gendolla, 2012).

A secondary aim of the study was to characterise the impact of alexithymia on the relationship between bodily changes and behaviors. Here, we found a trend of an interaction between alexithymia and systolic blood pressure. Compared to non-alexithymic, alexithymic individuals benefitted least from systolic blood pressure fluctuations. Alexithymia is classically characterized by increased blood pressure and reduced interoceptive abilities (Betka et al., 2017; Bornemann \& Singer, 2017; Brewer et al., 2016; Gage \& Egan, 1984; Jula et al., 1999; J. Murphy et al., 2017; Todarello et al., 1995). Given their atypical autonomic profiles, one could postulate that alexithymic people might also attribute less salience to bodily changes and show impaired integration of autonomic information when compared to non-alexithymic. 
Compensatory strategies developed by alexithymic individuals may explain, in part, why they are not impaired on the task. For example, alexithymic individual might use information related to bodily actions (e.g. increased somatosensory and motor areas activation) rather than affective states to correctly label emotional faces (Ihme et al., 2014). Alexithymic individuals may have particular difficulty in processing and automatically using high arousal emotional information in the context of cognitive challenges (Vermeulen et al., 2006). In that way, our data also suggest reduced integration of highly relevant emotional information in alexithymia. Further studies should clarify this relationship.

\subsection{Limitations}

Finally, we recognize limitations of our study. A larger sample might have increased statistical power and sensitivity to explore the impact of inter-individual characteristics on these relationships between body and behaviour. For example, it would have been interesting to measure trait anger and hostility, which is a factor known to modulate the effects of subliminal anger primes (Garfinkel et al., 2016; Wilkowski \& Robinson, 2008). Another limitation is that after calibrating the stimuli independently, we did not conduct an awareness check during the task to establish the degree to which the very brief (20ms) primes were processed unconsciously by each partcipant. We, therefore, cannot guarantee that our affective prime stimuli were rendered fully subliminal (van der Ploeg et al., 2017), although this would be unusual for our rapid presentation of the primes. Also, an objective measure of effort mobilization would have permitted us to interpret our results more confidently in the framework proposed by the IAPE model (Gendolla, 2012). Lastly, recent studies highlight the importance of taking in account both affective and cognitive dimensions of alexithymia as their autonomic signatures may differ (Cecchetto, Rumiati, \& Aiello, 2017; Martínez-Velázquez, Honoré, de Zorzi, Ramos-Loyo, \& Sequeira, 2017). We did not have this degree of granularity within the present dataset.

\subsection{Conclusion}


In conclusion, our data demonstrate the interacting effects of peripheral autonomic changes and affective states in guiding mental processes. A growing literature highlights atypical autonomic profiles across a wide range of psychiatric disorders. Future studies should, therefore, clarify the weight given to autonomic information in the generation of behavioural responses, in vulnerable populations. 


\section{Declarations of interest}

None.

Authors contribution

SB, SG, DD, HS and HDC were responsible for the study concept and design. SB and GP contributed to data acquisition. SB, DW and HDC assisted with data analysis and interpretation of findings. SB drafted the manuscript. DD, HS and HDC provided critical revision of the manuscript for important intellectual content. All authors critically reviewed content and approved final version for publication. 


\section{References}

Angrilli, A., Mini, A., Mucha, R. F., \& Rau, H. (1997). The influence of low blood pressure and baroreceptor activity on pain responses. Physiol Behav, 62(2), 391-397.

Apfel, R. J., \& Sifneos, P. E. (1979). Alexithymia: concept and measurement. Psychother Psychosom, 32(1-4), 180-190.

Bagby, R. M., Parker, J. D., \& Taylor, G. J. (1994). The twenty-item Toronto Alexithymia Scale--I. Item selection and cross-validation of the factor structure. J Psychosom Res, 38(1), 23-32.

Barr, D. J., Levy, R., Scheepers, C., \& Tily, H. J. (2013). Random effects structure for confirmatory hypothesis testing: Keep it maximal. J Mem Lang, 68(3). doi:10.1016/j.jml.2012.11.001

Bates, D., Maechler, M., Bolker, B., \& Walker, S. (2015). Fitting Linear Mixed-Effects Models Using Ime4. (67(1)). Journal of

Statistical Software.

Bechara, A., Tranel, D., Damasio, H., \& Damasio, A. R. (1996). Failure to respond autonomically to anticipated future outcomes following damage to prefrontal cortex. Cereb Cortex, 6(2), 215-225.

Beck, A. T., Steer, R. A., Ball, R., \& Ranieri, W. (1996). Comparison of Beck Depression Inventories -IA and -II in psychiatric outpatients. J Pers Assess, 67(3), 588-597. doi:10.1207/s15327752jpa6703_13

Betka, S., Pfeifer, G., Garfinkel, S., Prins, H., Bond, R., Sequeira, H., . . Critchley, H. (2017). How do selfassessment of alexithymia and sensitivity to bodily sensations relate to alcohol consumption? Alcohol Clin Exp Res. doi:10.1111/acer.13542

Bird, G., Silani, G., Brindley, R., White, S., Frith, U., \& Singer, T. (2010). Empathic brain responses in insula are modulated by levels of alexithymia but not autism. In Brain (Vol. 133, pp. 1515-1525).

Bornemann, B., \& Singer, T. (2017). Taking time to feel our body: Steady increases in heartbeat perception accuracy and decreases in alexithymia over 9 months of contemplative mental training. Psychophysiology, 54(3), 469-482. doi:10.1111/psyp.12790

Brading, A. (1999). The Autonomic Nervous System and Its Effectors. In. Oxford: Blackwell Science.

Brandt, L., Pintzinger, N. M., \& Tran, U. S. (2015). Abnormalities in Automatic Processing of IllnessRelated Stimuli in Self-Rated Alexithymia. PLoS One, 10(6), e0129905. doi:10.1371/journal.pone.0129905

Brewer, R., Cook, R., \& Bird, G. (2016). Alexithymia: a general deficit of interoception. In $R$ Soc Open Sci (Vol. 3).

Brooks, S. J., Savov, V., Allzen, E., Benedict, C., Fredriksson, R., \& Schioth, H. B. (2012). Exposure to subliminal arousing stimuli induces robust activation in the amygdala, hippocampus, anterior cingulate, insular cortex and primary visual cortex: a systematic meta-analysis of fMRI studies. Neuroimage, 59(3), 2962-2973. doi:10.1016/j.neuroimage.2011.09.077

Burra, N., Barras, C., Coll, S. Y., \& Kerzel, D. (2016). Electrophysiological evidence for attentional capture by irrelevant angry facial expressions. Biol Psychol, 120, 69-80. doi:10.1016/j.biopsycho.2016.08.008

Burra, N., Coll, S. Y., Barras, C., \& Kerzel, D. (2017). Electrophysiological evidence for attentional capture by irrelevant angry facial expressions: Naturalistic faces. Neurosci Lett, 637, 44-49. doi:10.1016/j.neulet.2016.11.055

Byrne, N., \& Ditto, B. (2005). Alexithymia, cardiovascular reactivity, and symptom reporting during blood donation. Psychosom Med, 67(3), 471-475. doi:10.1097/01.psy.0000160471.66399.12

Carver, C. S., \& Harmon-Jones, E. (2009). Anger is an approach-related affect: evidence and implications. Psychol Bull, 135(2), 183-204. doi:10.1037/a0013965 
Cecchetto, C., Korb, S., Rumiati, R. I., \& Aiello, M. (2018). Emotional reactions in moral decision-making are influenced by empathy and alexithymia. Soc Neurosci, 13(2), 226-240. doi:10.1080/17470919.2017.1288656

Cecchetto, C., Rumiati, R. I., \& Aiello, M. (2017). Alexithymia and emotional reactions to odors. In Sci Rep (Vol. 7).

Cellini, N., Covassin, N., de Zambotti, M., Sarlo, M., \& Stegagno, L. (2013). Relationship between cardiovascular resting state and visual attention. Clin Auton Res, 23(3), 157-161. doi:10.1007/s10286-013-0194-x

Chatelain, M., Silvestrini, N., \& Gendolla, G. H. (2016). Task difficulty moderates implicit fear and anger effects on effort-related cardiac response. Biol Psychol, 115, 94-100. doi:10.1016/j.biopsycho.2016.01.014

Constantinou, E., Panayiotou, G., \& Theodorou, M. (2014). Emotion processing deficits in alexithymia and response to a depth of processing intervention. Biol Psychol, 103, 212-222. doi:10.1016/j.biopsycho.2014.09.011

Critchley, H. D., \& Harrison, N. A. (2013). Visceral influences on brain and behavior. Neuron, 77(4), 624638. doi:10.1016/j.neuron.2013.02.008

Duschek, S., Hadjamu, M., \& Schandry, R. (2007). Enhancement of cerebral blood flow and cognitive performance following pharmacological blood pressure elevation in chronic hypotension. Psychophysiology, 44(1), 145-153. doi:10.1111/j.1469-8986.2006.00472.x

Eckberg, D., \& Sleight, P. (1992). Human Baroreflexes in Health and Disease. In. Oxford: Clarendon Press.

Feldmann-Wustefeld, T., Schmidt-Daffy, M., \& Schubo, A. (2011). Neural evidence for the threat detection advantage: differential attention allocation to angry and happy faces. Psychophysiology, 48(5), 697-707. doi:10.1111/j.1469-8986.2010.01130.x

Finn, P. R., Martin, J., \& Pihl, R. O. (1987). Alexithymia in males at high genetic risk for alcoholism. Psychother Psychosom, 47(1), 18-21.

Freydefont, L., Gendolla, G. H., \& Silvestrini, N. (2012). Beyond valence: the differential effect of masked anger and sadness stimuli on effort-related cardiac response. Psychophysiology, 49(5), 665-671. doi:10.1111/j.1469-8986.2011.01340.x

Gage, B. C., \& Egan, K. J. (1984). The effect of alexithymia on morbidity in hypertensives. Psychother Psychosom, 41(3), 136-144.

Garfinkel, S. N., Zorab, E., Navaratnam, N., Engels, M., Mallorqui-Bague, N., Minati, L., . . Critchley, H. D. (2016). Anger in brain and body: the neural and physiological perturbation of decision-making by emotion. Soc Cogn Affect Neurosci, 11(1), 150-158. doi:10.1093/scan/nsv099

Gendolla, G. H. (2012). Implicit affect primes effort: a theory and research on cardiovascular response. Int J Psychophysiol, 86(2), 123-135. doi:10.1016/j.ijpsycho.2012.05.003

Gendolla, G. H., \& Silvestrini, N. (2011). Smiles make it easier and so do frowns: masked affective stimuli influence mental effort. Emotion, 11(2), 320-328. doi:10.1037/a0022593

Georgiou, E., Mai, S., \& Pollatos, O. (2016). Describe Your Feelings: Body Illusion Related to Alexithymia in Adolescence. Front Psychol, 7. doi:10.3389/fpsyg.2016.01690

Goeleven, E., De Raedt, R., Leyman, L., \& Verschuere, B. (2008). The Karolinska Directed Emotional Faces: A validation study. (22(6)). Cognition \& Emotion.

Gray, M. A., Minati, L., Paoletti, G., \& Critchley, H. D. (2010). Baroreceptor activation attenuates attentional effects on pain-evoked potentials. In Pain (Vol. 151, pp. 853-861).

Grynberg, D., Chang, B., Corneille, O., Maurage, P., Vermeulen, N., Berthoz, S., \& Luminet, O. (2012). Alexithymia and the processing of emotional facial expressions (EFEs): systematic review, unanswered questions and further perspectives. PLoS One, 7(8), e42429. doi:10.1371/journal.pone.0042429 
Grynberg, D., \& Pollatos, O. (2015). Alexithymia modulates the experience of the rubber hand illusion. Front Hum Neurosci, 9. doi:10.3389/fnhum.2015.00357

Hare, R., Wood, K., Britain, S., \& Shadman, J. (1970). Autonomic responses to affective visual stimulation. Psychophysiology, 7(3), 408-417.

Haviland, M. G., Shaw, D. G., MacMurray, J. P., \& Cummings, M. A. (1988). Validation of the Toronto Alexithymia Scale with substance abusers. Psychother Psychosom, 50(2), 81-87.

Helmers, K. F., \& Mente, A. (1999). Alexithymia and health behaviors in healthy male volunteers. $J$ Psychosom Res, 47(6), 635-645.

Hendryx, M. S., Haviland, M. G., \& Shaw, D. G. (1991). Dimensions of alexithymia and their relationships to anxiety and depression. J Pers Assess, 56(2), 227-237. doi:10.1207/s15327752jpa5602_4

Hodsoll, S., Viding, E., \& Lavie, N. (2011). Attentional capture by irrelevant emotional distractor faces. Emotion, 11(2), 346-353. doi:10.1037/a0022771

Hogeveen, J., Bird, G., Chau, A., Krueger, F., \& Grafman, J. (2016). Acquired alexithymia following damage to the anterior insula. Neuropsychologia, 82, 142-148. doi:10.1016/j.neuropsychologia.2016.01.021

Hortensius, R., de Gelder, B., \& Schutter, D. (2016). When anger dominates the mind: Increased motor corticospinal excitability in the face of threat. In Psychophysiology (Vol. 53, pp. 1307-1316).

Hull, J. G., Slone, L. B., Meteyer, K. B., \& Matthews, A. R. (2002). The nonconsciousness of selfconsciousness. J Pers Soc Psychol, 83(2), 406-424.

Ihme, K., Sacher, J., Lichev, V., Rosenberg, N., Kugel, H., Rufer, M., . . Suslow, T. (2014). Alexithymia and the labeling of facial emotions: response slowing and increased motor and somatosensory processing. BMC Neurosci, 15, 40. doi:10.1186/1471-2202-15-40

Jackson, M. C., Wolf, C., Johnston, S. J., Raymond, J. E., \& Linden, D. E. (2008). Neural correlates of enhanced visual short-term memory for angry faces: an FMRI study. PLoS One, 3(10), e3536. doi:10.1371/journal.pone.0003536

Jackson, M. C., Wu, C. Y., Linden, D. E., \& Raymond, J. E. (2009). Enhanced visual short-term memory for angry faces. J Exp Psychol Hum Percept Perform, 35(2), 363-374. doi:10.1037/a0013895

James, W. (1884). What is an emotion? , (9, 34). Mind.

Jula, A., Salminen, J. K., \& Saarijarvi, S. (1999). Alexithymia: a facet of essential hypertension. Hypertension, 33(4), 1057-1061.

Kauhanen, J., Kaplan, G. A., Cohen, R. D., Julkunen, J., \& Salonen, J. T. (1996). Alexithymia and risk of death in middle-aged men. J Psychosom Res, 41(6), 541-549.

Kauhanen, J., Kaplan, G. A., Cohen, R. D., Salonen, R., \& Salonen, J. T. (1994). Alexithymia may influence the diagnosis of coronary heart disease. Psychosom Med, 56(3), 237-244.

Kimmerly, D. S. (2017). A review of human neuroimaging investigations involved with central autonomic regulation of baroreflex-mediated cardiovascular control. Auton Neurosci. doi:10.1016/j.autneu.2017.05.008

Kuznetsova, A., Brockhoff, P. B., \& Christensen, R. H. B. (2014). ImerTest: Tests for Random and Fixed Effects for Linear Mixed Effect Models (Lmer Objects of Lme4 Package). R Package Version

2.0-6 Available online at: http://cran.r-project.org/web/packages/ImerTest/index.html. In.

Lacey, J., \& Lacey, B. C. (1970). Some autonomic-central nervous system interrelationships (P. B. (Ed.) Ed.). Academic Press, New York.

Laguna, P., Moody, G. B., \& Mark, R. G. (1998). Power spectral density of unevenly sampled data by least-square analysis: performance and application to heart rate signals. IEEE Trans Biomed Eng, 45(6), 698-715. doi:10.1109/10.678605 
Lane, R. D., Hsu, C. H., Locke, D. E., Ritenbaugh, C., \& Stonnington, C. M. (2015). Role of theory of mind in emotional awareness and alexithymia: Implications for conceptualization and measurement. Conscious Cogn, 33, 398-405. doi:10.1016/j.concog.2015.02.004

Lange, C. G. (1912). The mechanism of emotions (B.Rand, Trans.) In B.Rand (Ed.). Copenhagen.

Lasauskaite, R., Gendolla, G. H., \& Silvestrini, N. (2013). Do sadness-primes make me work harder because they make me sad? Cogn Emot, 27(1), 158-165. doi:10.1080/02699931.2012.689756

Libby, W. L., Jr., Lacey, B. C., \& Lacey, J. I. (1973). Pupillary and cardiac activity during visual attention. Psychophysiology, 10(3), 270-294.

Little, R. J. (1988). Missing-data adjustments in large surveys. Journal of Business \& Economic Statistics, 6(3), 287-296.

Lo, S., \& Andrews, S. (2015). To transform or not to transform: using generalized linear mixed models to analyse reaction time data. Front Psychol, 6. doi:10.3389/fpsyg.2015.01171

Makovac, E., Garfinkel, S., Bassi, A., Basile, B., Macaluso, E., Cercignani, M., . . Bozzali, M. (2017). Fear processing is differentially affected by lateralized stimulation of carotid baroreceptors. Cortex, 99, 200-212. doi:10.1016/j.cortex.2017.07.002

Makovac, E., Garfinkel, S. N., Bassi, A., Basile, B., Macaluso, E., Cercignani, M., . . Critchley, H. (2015). Effect of parasympathetic stimulation on brain activity during appraisal of fearful expressions. Neuropsychopharmacology, 40(7), 1649-1658. doi:10.1038/npp.2015.10

Martínez-Velázquez, E. S., Honoré, J., de Zorzi, L., Ramos-Loyo, J., \& Sequeira, H. (2017). Autonomic Reactivity to Arousing Stimuli with Social and Non-social Relevance in Alexithymia. Front Psychol, 8. doi:10.3389/fpsyg.2017.00361

McCubbin, J. A., Merritt, M. M., Sollers, J. J., Evans, M. K., Zonderman, A. B., Lane, R. D., \& Thayer, J. F. (2011). Cardiovascular Emotional Dampening: The Relationship between Blood Pressure and Recognition of Emotion. Psychosom Med, 73(9), 743-750. doi:10.1097/PSY.0b013e318235ed55

Mehrabian, A., \& Russell, J. A. (1978). A questionnaire measure of habitual alcohol use. Psychol Rep, 43(3 Pt 1), 803-806. doi:10.2466/pr0.1978.43.3.803

Moriguchi, Y., Decety, J., Ohnishi, T., Maeda, M., Mori, T., Nemoto, K., . . Komaki, G. (2007). Empathy and judging other's pain: an fMRI study of alexithymia. Cereb Cortex, 17(9), 2223-2234. doi:10.1093/cercor/bhl130

Murphy, J., Catmur, C., \& Bird, G. (2017). Alexithymia is associated with a multi-domain, multidimensional failure of interoception: evidence from novel tests. Journal of Experimental Psychology: General.

Murphy, S. T., \& Zajonc, R. B. (1993). Affect, cognition, and awareness: affective priming with optimal and suboptimal stimulus exposures. J Pers Soc Psychol, 64(5), 723-739.

Mussalo, H., Vanninen, E., Ikaheimo, R., Laitinen, T., Laakso, M., Lansimies, E., \& Hartikainen, J. (2002). Baroreflex sensitivity in essential and secondary hypertension. Clin Auton Res, 12(6), 465-471. doi:10.1007/s10286-002-0069-z

Neumann, S. A., Sollers, J. J., 3rd, Thayer, J. F., \& Waldstein, S. R. (2004). Alexithymia predicts attenuated autonomic reactivity, but prolonged recovery to anger recall in young women. Int $J$ Psychophysiol, 53(3), 183-195. doi:10.1016/j.ijpsycho.2004.03.008

Obrist, P. A., Lawler, J. E., Howard, J. L., Smithson, K. W., Martin, P. L., \& Manning, J. (1974). Sympathetic influences on cardiac rate and contractility during acute stress in humans. Psychophysiology, 11(4), 405-427.

Paller, K., \& Shapiro, D. (1983). Systolic blood pressure and a simple reaction time task. Psychophysiology, 20(5), 585-590.

Park, G., \& Thayer, J. F. (2014). From the heart to the mind: cardiac vagal tone modulates top-down and bottom-up visual perception and attention to emotional stimuli. Front Psychol, 5. doi:10.3389/fpsyg.2014.00278 
Park, G., Vasey, M. W., Van Bavel, J. J., \& Thayer, J. F. (2013). Cardiac vagal tone is correlated with selective attention to neutral distractors under load. Psychophysiology, 50(4), 398-406. doi:10.1111/psyp.12029

Park, H. D., Correia, S., Ducorps, A., \& Tallon-Baudry, C. (2014). Spontaneous fluctuations in neural responses to heartbeats predict visual detection. Nat Neurosci, 17(4), 612-618. doi:10.1038/nn.3671

Peasley-Miklus, C. E., Panayiotou, G., \& Vrana, S. R. (2016). Alexithymia predicts arousal-based processing deficits and discordance between emotion response systems during emotional imagery. Emotion, 16(2), 164-174. doi:10.1037/emo0000086

Pinkham, A. E., Griffin, M., Baron, R., Sasson, N. J., \& Gur, R. C. (2010). The face in the crowd effect: anger superiority when using real faces and multiple identities. Emotion, 10(1), 141-146. doi:10.1037/a0017387

Pollatos, O., Werner, N. S., Duschek, S., Schandry, R., Matthias, E., Traut-Mattausch, E., \& Herbert, B. M. (2011). Differential effects of alexithymia subscales on autonomic reactivity and anxiety during social stress. J Psychosom Res, 70(6), 525-533. doi:10.1016/j.jpsychores.2010.12.003

Pury, C. L., McCubbin, J. A., Helfer, S. G., Galloway, C., \& McMullen, L. J. (2004). Elevated resting blood pressure and dampened emotional response. Psychosom Med, 66(4), 583-587. doi:10.1097/01.psy.0000130490.57706.88

Ramshur, J. Design, evaluation, and application of heart rate variability analysis software (HRVAS). Retrieved from http://sourceforge.net/projects/hrvas/?source=navbar

Rau, H., Pauli, P., Brody, S., Elbert, T., \& Birbaumer, N. (1993). Baroreceptor stimulation alters cortical activity. Psychophysiology, 30(3), 322-325.

RCoreTeam. (2013). R: A language and Environment for Statistical Computing. R Foundation for Statistical Computing; Vienna:Available online at: http://www.R-project.org.

Russell, J. A. (2003). Core affect and the psychological construction of emotion. Psychol Rev, 110(1), 145172.

Scarpazza, C., Ladavas, E., \& Cattaneo, L. (2017). Invisible side of emotions: somato-motor responses to affective facial displays in alexithymia. Exp Brain Res. doi:10.1007/s00221-017-5118-x

Scarpazza, C., Ladavas, E., \& di Pellegrino, G. (2015). Dissociation between Emotional Remapping of Fear and Disgust in Alexithymia. PLoS One, 10(10), e0140229. doi:10.1371/journal.pone.0140229

Shah, P., Catmur, C., \& Bird, G. (2017). From heart to mind: Linking interoception, emotion, and theory of mind. In Cortex (Vol. 93, pp. 220-223).

Shah, P., Hall, R., Catmur, C., \& Bird, G. (2016). Alexithymia, not autism, is associated with impaired interoception. Cortex, 81, 215-220. doi:10.1016/j.cortex.2016.03.021

Shasteen, J. R., Sasson, N. J., \& Pinkham, A. E. (2014). Eye tracking the face in the crowd task: why are angry faces found more quickly? PLoS One, 9(4), e93914. doi:10.1371/journal.pone.0093914

Silvestrini, N., \& Gendolla, G. H. (2011a). beta-adrenergic impact underlies the effect of mood and hedonic instrumentality on effort-related cardiovascular response. Biol Psychol, 87(2), 209-217. doi:10.1016/j.biopsycho.2011.02.017

Silvestrini, N., \& Gendolla, G. H. (2011b). Do not prime too much: Prime frequency effects of masked affective stimuli on effort-related cardiovascular response. Biol Psychol, 87(2), 195-199. doi:10.1016/j.biopsycho.2011.01.006

Silvestrini, N., \& Gendolla, G. H. (2011c). Masked affective stimuli moderate task difficulty effects on effort-related cardiovascular response. Psychophysiology, 48(8), 1157-1164. doi:10.1111/j.14698986.2011.01181.x

Spielberger, C. D., Gorsuch, L, R., Lushene, R, Vagg, . . A, G. (1983). Manual for the State-Trait Anxiety Inventory. Palo Alto: CA: Consulting 
Psychologists Press.

Sternberg, S. (1966). High-speed scanning in human memory. Science, 153(3736), 652-654.

Suslow, T. (1998). Alexithymia and automatic affective processing., (12). European Journal of Personality.

Suslow, T., Junghanns, K., Donges, U., \& Arolt, V. (2001). Alexithymia and automatic processing of verbal and facial affect stimuli. (20). Current Psychology of Cognition.

Taylor, G. J., Bagby, R. M., Ryan, D. P., Parker, J. D., Doody, K. F., \& Keefe, P. (1988). Criterion validity of the Toronto Alexithymia Scale. Psychosom Med, 50(5), 500-509.

Taylor, G. J., Ryan, D., \& Bagby, R. M. (1985). Toward the development of a new self-report alexithymia scale. Psychother Psychosom, 44(4), 191-199.

Todarello, O., Taylor, G. J., Parker, J. D., \& Fanelli, M. (1995). Alexithymia in essential hypertensive and psychiatric outpatients: a comparative study. J Psychosom Res, 39(8), 987-994.

Tolmunen, T., Lehto, S. M., Heliste, M., Kurl, S., \& Kauhanen, J. (2010). Alexithymia is associated with increased cardiovascular mortality in middle-aged Finnish men. Psychosom Med, 72(2), 187-191. doi:10.1097/PSY.0b013e3181c65d00

Tsakiris, M., \& Critchley, H. (2016). Interoception beyond homeostasis: affect, cognition and mental health. In Philos Trans R Soc Lond B Biol Sci (Vol. 371).

Van Buuren, S., \& Groothuis-Oudshoorn, K. (2011). Mice:Multivariate Imputation by Chained Equations in R. In (Vol. 45(3), pp. 1-67). Journal of Statistical Software.

van der Ploeg, M. M., Brosschot, J. F., Versluis, A., \& Verkuil, B. (2017). Peripheral physiological responses to subliminally presented negative affective stimuli: A systematic review. Biol Psychol, 129, 131-153. doi:10.1016/j.biopsycho.2017.08.051

Vermeulen, N., Luminet, O., \& Corneille, O. (2006). Alexithymia and the automatic processing of affective information: Evidence from the affective priming paradigm., (20). Cognition \& Emotion.

Virtanen, R., Jula, A., Salminen, J. K., Voipio-Pulkki, L. M., Helenius, H., Kuusela, T., \& Airaksinen, J. (2003). Anxiety and hostility are associated with reduced baroreflex sensitivity and increased beat-to-beat blood pressure variability. Psychosom Med, 65(5), 751-756.

Wharton, W., Hirshman, E., Merritt, P., Stangl, B., Scanlin, K., \& Krieger, L. (2006). Lower blood pressure correlates with poorer performance on visuospatial attention tasks in younger individuals. Biol Psychol, 73(3), 227-234. doi:10.1016/j.biopsycho.2006.04.002

Whelan, R. (2008). Effective analysis of reaction time data. In (Vol. 58, pp. 475-482). The psychological record.

Wilkowski, B. M., \& Meier, B. P. (2010). Bring it on: angry facial expressions potentiate approachmotivated motor behavior. J Pers Soc Psychol, 98(2), 201-210. doi:10.1037/a0017992

Wilkowski, B. M., \& Robinson, M. D. (2008). The cognitive basis of trait anger and reactive aggression: an integrative analysis. Pers Soc Psychol Rev, 12(1), 3-21. doi:10.1177/1088868307309874

Winkielman, P., Berridge, K. C., \& Wilbarger, J. L. (2005). Unconscious affective reactions to masked happy versus angry faces influence consumption behavior and judgments of value. Pers Soc Psychol Bull, 31(1), 121-135. doi:10.1177/0146167204271309

Yoris, A., Abrevaya, S., Esteves, S., Salamone, P., Lori, N., Martorell, M., . . Ibanez, A. (2017). Multilevel convergence of interoceptive impairments in hypertension: New evidence of disrupted bodybrain interactions. Hum Brain Mapp. doi:10.1002/hbm.23933

Łukowska, M., Sznajder, M., \& Wierzchoń, M. (2018). Error-related cardiac response as information for visibility judgements. Scientific Reports, 8(1), 1131. doi:10.1038/s41598-018-19144-0 


\section{Tables}

Table 1

\begin{tabular}{|c|c|c|c|c|c|c|c|c|c|c|c|}
\hline & & 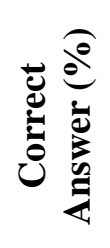 & 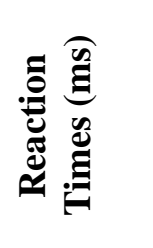 & 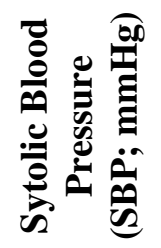 & 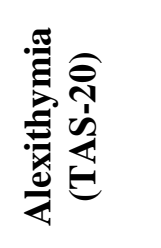 & 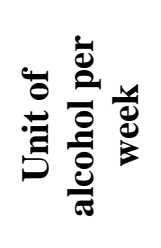 & 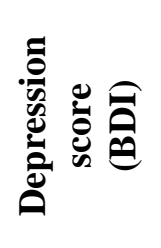 & $\sum_{\tilde{E}}^{\Xi}$ & 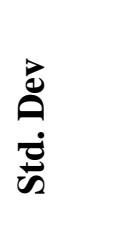 & 声 & 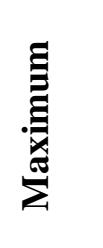 \\
\hline Correct Answer (\%) & $\begin{array}{l}\tau \\
p\end{array}$ & - & & & & & & 83.47 & 8.80 & 54.17 & 97.92 \\
\hline Reaction Times (s) & $\begin{array}{l}\tau \\
p\end{array}$ & $\begin{array}{l}-0.09 \\
0.484\end{array}$ & - & & & & & $\begin{array}{c}1020.3 \\
0\end{array}$ & $\begin{array}{c}139.6 \\
7\end{array}$ & 730 & 1380 \\
\hline $\begin{array}{l}\text { Sytolic Blood Pressure } \\
\text { (SBP; mmHg) }\end{array}$ & $\tau$ & $\begin{array}{c}- \\
0.108 \\
0.403\end{array}$ & $\begin{array}{c}0.11 \\
0.386\end{array}$ & $\begin{array}{l}- \\
\text {. }\end{array}$ & & & & 125 & 19 & 78 & 161 \\
\hline Alexithymia (TAS-20) & $\tau$ & $\begin{array}{c}- \\
0.173 \\
0.183\end{array}$ & $\begin{array}{l}0.128 \\
0.315\end{array}$ & $\begin{array}{l}-0.08 \\
0.529\end{array}$ & - & & & 55.13 & 9.69 & 36 & 74 \\
\hline $\begin{array}{c}\text { Unit of alcohol per } \\
\text { week }\end{array}$ & $\begin{array}{l}\tau \\
p\end{array}$ & $\begin{array}{l}0.037 \\
0.772\end{array}$ & $\begin{array}{c}0.131 \\
0.3\end{array}$ & $\begin{array}{l}0.153 \\
0.228\end{array}$ & $\begin{array}{l}0.063 \\
0.622\end{array}$ & - & & 24.57 & 18.32 & 4.5 & 69.5 \\
\hline Depression score (BDI) & $\tau$ & $\begin{array}{c}- \\
0.114 \\
0.383\end{array}$ & 0.039 & -0.079 & 0.041 & $\begin{array}{l}-0.039 \\
0.759\end{array}$ & - & 11.58 & 7.57 & 0 & 29 \\
\hline Trait Anxiety (STAI) & $\tau$ & $\begin{array}{c}0.11 \\
0.401\end{array}$ & $\begin{array}{l}0.064 \\
0.621\end{array}$ & $\begin{array}{l}-0.125 \\
0.331\end{array}$ & $\begin{array}{l}0.162 \\
0.213\end{array}$ & $\begin{array}{r}-0.086 \\
0.506\end{array}$ & $\begin{array}{r}.450 \\
0.001\end{array}$ & 47.71 & 12.31 & 22 & 66 \\
\hline
\end{tabular}


Table 2

\begin{tabular}{|c|c|c|c|c|c|}
\hline & $\beta$ & SE & $\mathbf{z}$ & $p$ & \\
\hline Intercept & 1.56 & 0.13 & 12.25 & $<0.001$ & $* * *$ \\
\hline Sadness & -0.01 & 0.12 & -0.09 & 0.93 & \\
\hline Anger & 0.49 & 0.13 & 3.80 & $<0.001$ & $* * *$ \\
\hline $\begin{array}{l}\text { Systolic Blood pressure } \\
\text { (SBP) }\end{array}$ & 1.56 & 0.60 & 2.59 & 0.01 & $*$ \\
\hline TAS-20 & 0.01 & 0.01 & 0.51 & 0.61 & \\
\hline Age & -0.06 & 0.03 & -2.28 & 0.02 & $*$ \\
\hline Sadness:SBP & -0.59 & 0.59 & -1.01 & 0.31 & \\
\hline Anger:SBP & -1.14 & 0.64 & -1.79 & 0.07 & . \\
\hline Sadness:TAS-20 & -0.01 & 0.01 & -1.03 & 0.30 & \\
\hline Anger:TAS-20 & -0.01 & 0.01 & -0.77 & 0.44 & \\
\hline SBP:TAS-20 & -0.10 & 0.05 & -1.90 & 0.06 & . \\
\hline Sadness:SBP:TAS-20 & 0.04 & 0.05 & 0.92 & 0.36 & \\
\hline Anger:SBP:TAS-20 & -0.02 & 0.06 & -0.39 & 0.70 & \\
\hline
\end{tabular}


Table 3

\begin{tabular}{|c|c|c|c|c|c|}
\hline & $\beta$ & SE & $\mathbf{z}$ & $p$ & \\
\hline Intercept & 1.01 & 0.03 & 30.08 & $<0.001$ & $* * *$ \\
\hline Sadness & -0.01 & 0.01 & -1.03 & 0.30 & \\
\hline Anger & 0.00 & 0.01 & -0.07 & 0.95 & \\
\hline $\begin{array}{l}\text { Systolic Blood pressure } \\
\text { (SBP) }\end{array}$ & -0.14 & 0.08 & -1.69 & 0.09 & . \\
\hline TAS-20 & 0.00 & 0.00 & -0.51 & 0.61 & \\
\hline Age & 0.00 & 0.01 & 0.26 & 0.79 & \\
\hline Sadness:SBP & 0.20 & 0.06 & 3.36 & $<0.001$ & $* * *$ \\
\hline Anger:SBP & -0.01 & 0.06 & -0.19 & 0.85 & \\
\hline Sadness:TAS-20 & 0.00 & 0.00 & 0.94 & 0.35 & \\
\hline Anger:TAS-20 & 0.00 & 0.00 & -1.01 & 0.31 & \\
\hline SBP:TAS-20 & -0.01 & 0.01 & -1.23 & 0.22 & \\
\hline Sadness:SBP:TAS-20 & -0.01 & 0.00 & -1.58 & 0.11 & \\
\hline Anger:SBP:TAS-20 & 0.00 & 0.00 & 0.27 & 0.79 & \\
\hline
\end{tabular}


Table 4

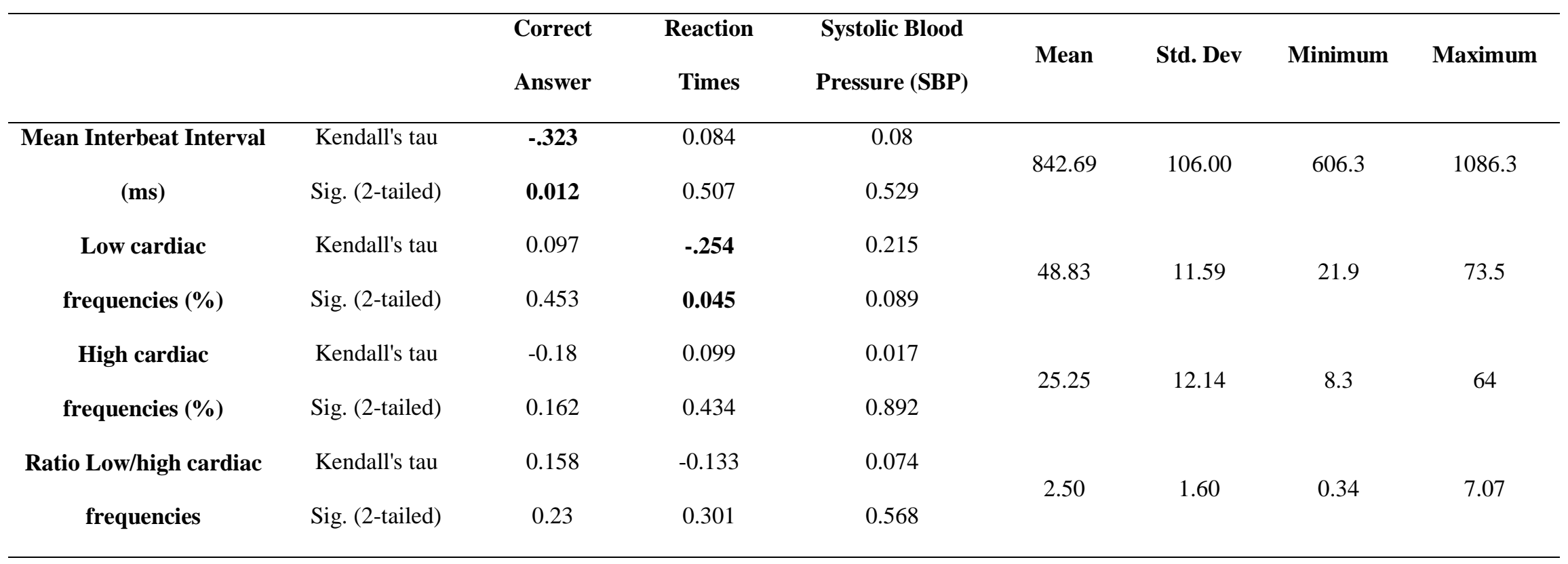




\section{Tables Legends}

Table 1: Mean, standard deviations, range as well as uncorrected Kendall's tau correlation coefficients for psychometric, physiological and behavioural measures

Table 2: Mixed-effects regression model to explain accuracy, using Emotion (Neutrality, Sadness, Anger), systolic blood pressure (SBP) alexithymia (TAS-20) and their interactions as predictors, and, age as control variable. signif. codes: 0 “***’ 0.001 '**' 0.01 '*' 0.05 ' 90.1

Table 3: Mixed-effects regression model to explain reaction times, using Emotion (Neutrality, Sadness, Anger), systolic blood pressure (SBP) alexithymia (TAS-20) and their interactions as predictors, and, age as control variable. signif. codes: 0 ‘***’ 0.001 '**' 0.01 '*’ 0.05 ‘’ 0.1

Table 4: Mean, standard deviations, range as well as Kendall's tau correlation coefficients for heart rate variability-related and behavioural measures. 


\section{Figure Legends}

Figure 1: Main effect of emotion on probability of being accurate $(* * * p<.001)$

Figure 2: Trend of interaction between systolic blood pressure and emotion on probability of being accurate $(p=.070)$

Figure 3: Trend of interaction between systolic blood pressure and Alexithymia (TAS-20 scores) on probability of being accurate $(p=.058)$. To illustrate this interaction, high alexithymic (represented by Mean TAS-20 score $+1 \mathrm{SD}=65$ ), intermediate (represented by Mean TAS-20 score $=55$ ) and non alexithymic (represented by Mean TAS-20 score $-1 \mathrm{SD}=45$ ) were plotted.

Figure 4: Interaction between systolic blood pressure and emotion on reaction times $(p<.001)$ 
bioRxiv preprint doi: https://doi.org/10.1101/2021.10.22.465429; this version posted October 27, 2021. The copyright holder for this preprint (which was not certified by peer review) is the author/funder, who has granted bioRxiv a license to display the preprint in perpetuity. It is made available under aCC-BY-NC 4.0 International license.
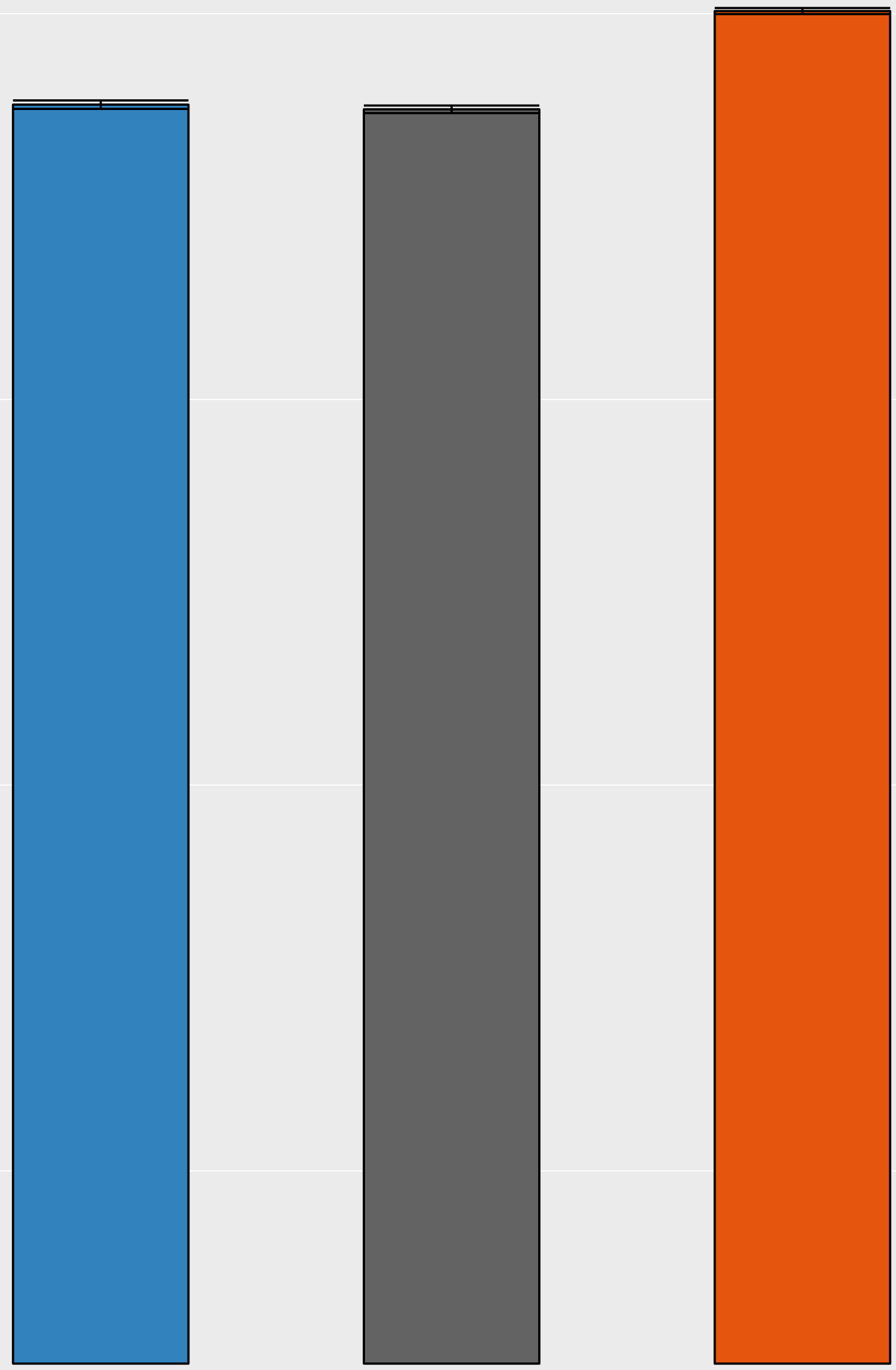

\section{Emotions}




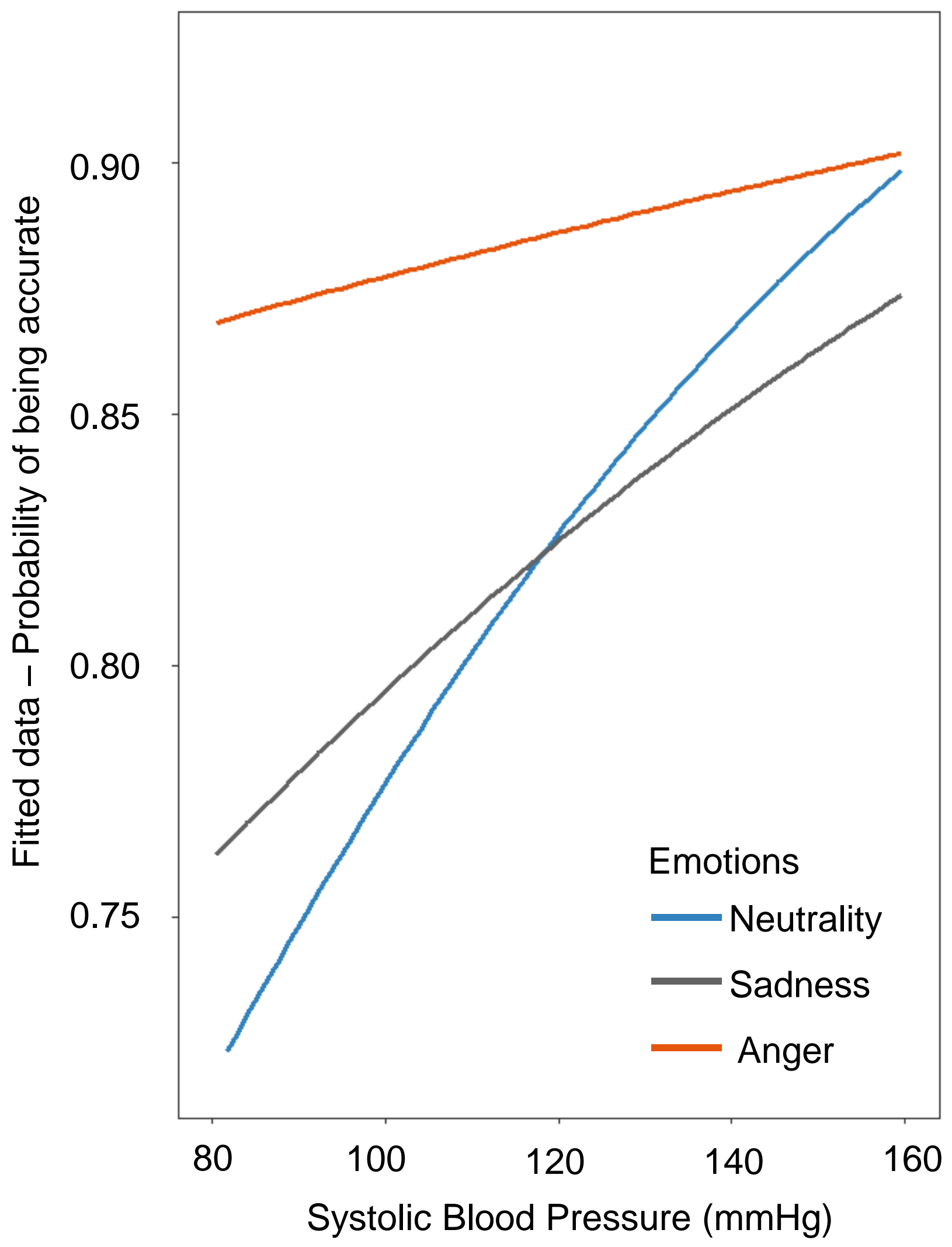




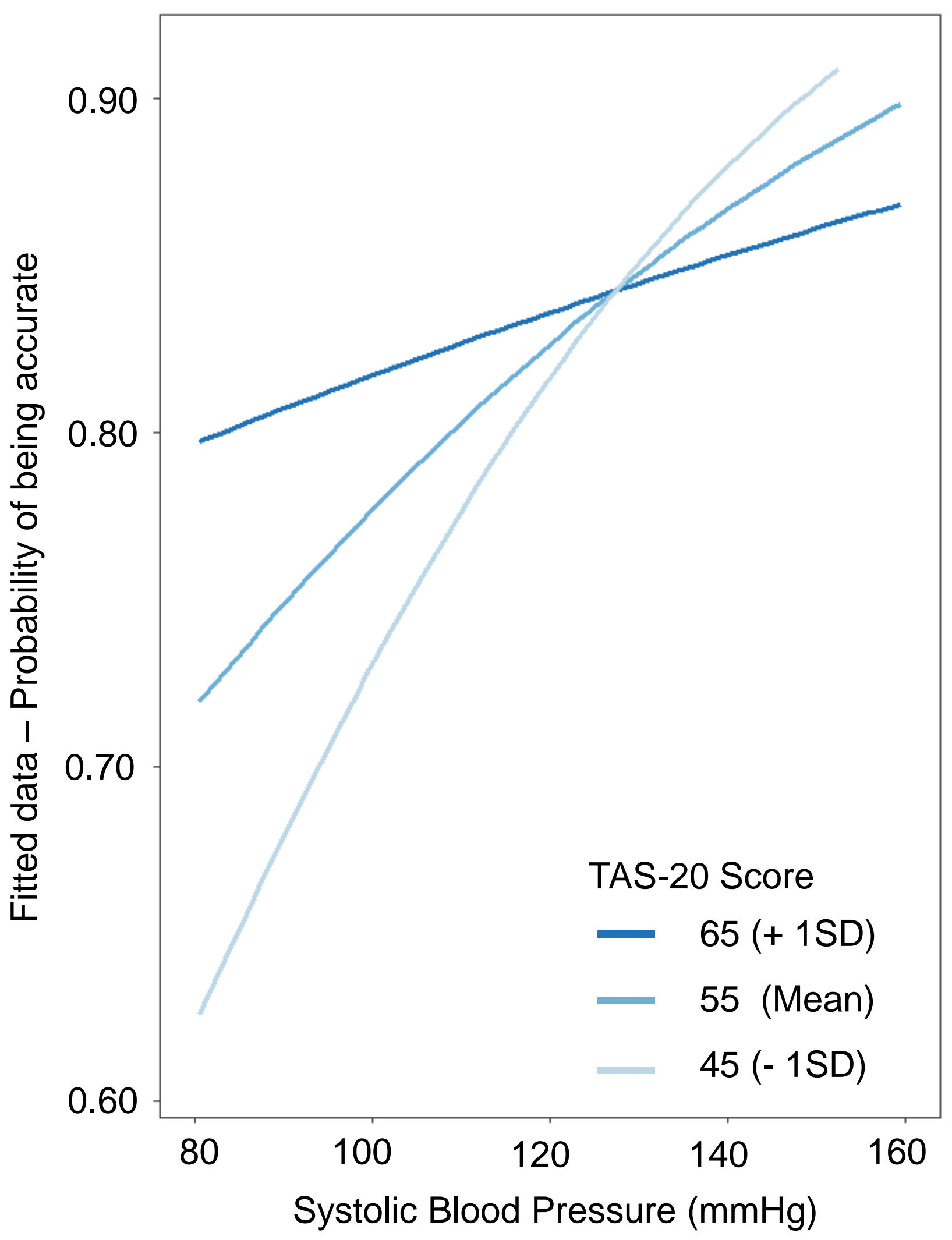


(which was not certified by peer review) is the author/funder, who has granted bioRxiv a license to display the preprint in perpetuity. It is $m$ 1075 available under aCC-BY-NC 4.0 International license.

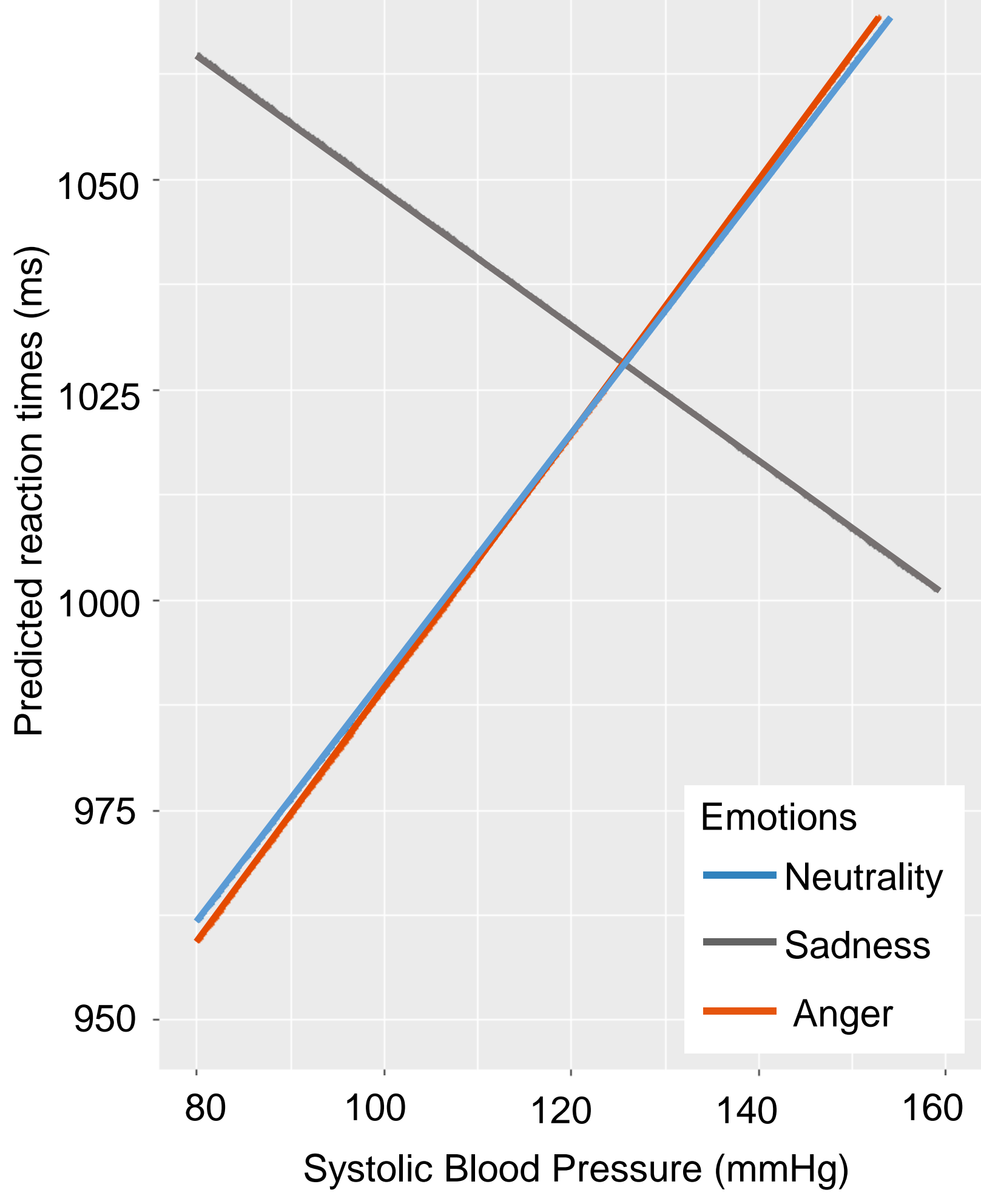

